\title{
Increased Crown-Size Asymmetry in Trisomy G
}

\author{
STANLEY M. GARN, M. MICHAEL COHEN, and MICHAEL A. GECIAUSKAS \\ Center for Human Growth and Development, University of Michigan, Ann Arbor and De- \\ partment of Oral Pathology, Tufts University, Boston, Massachusetts 02111
}

Trisomy G (Down's syndrome or "mongolism") is associated with multiple dental abnormalities (J. Oster, Mongolism, Copenhagen: Danish Science Press, 1953). Teeth are frequently missing, all morphologic classes are involved, and the remaining teeth are characterized by size reduction (M. M. CoHEN and A. WINER, J Dent Res 44:197-208, 1965; and M. M. CoHEN, S. M. GarN, and M. A. Geciauskas, J Dent Res 49:460, 1970). One might therefore expect an increase in the magnitude of bilateral (leftright) crown-size asymmetry, especially for the more variable lateral tooth of each morphologic class.

To test this hypothesis we calculated individual left-right crown size asymmetry values (d) for paired antimeres in 47 instances of trisomy $G$. Nineteen of these verified instances were in males and 28 were in females. For each tooth pair the RMS (root mean square) asymmetry value $\left(\sigma_{d}\right)$ for the mesiodistal crown diameter was computed as previously described. (S. M. GARN, A. B. LewIS, and R. KEREWSKY, Angle Ortho 36:55-62, 1966). The sex- and tooth-specific values of RMS asymmetry in the subjects with trisomy $G$ were then compared to the "normal" values, previously published.

As shown in the table, crown-size asymmetry of the permanent teeth in subjects with Down's syndrome systematically exceeds RMS bilateral asymmetry of normal subjects. This is true for all 14 teeth considered, and in both sexes, with an observed ratio of $28: 0$ as against the $14: 14$ or chance hypothesis. Furthermore, the magnitude of RMS asymmetry in these 47 subjects

Statistical analysis was supported by USPHS Research Grant HD-02272 from the National Institute of Child Health and Human Development, Bethesda, Md. Additional information available on request to authors. Received for publication August 27, 1969.

William R. D'Angelo of the Growth Center Computer Group completed the statistical analysis. with trisomy $\mathrm{G}$ is close to twice that of the normal population. Class by class, the relative bilateral asymmetry in subjects with trisomy $G$ is elevated for $I^{2}$ as against $I^{1}$, for $\mathbf{M}_{2}$ as against $M_{1}$ and $P_{2}$ as against $P_{1}$, but not for $I_{2}$ against $I_{1}$ or $P^{2}$ against $P^{1}$.

Accordingly, it is clear that bilateral RMS crown-size asymmetry is decidedly increased in trisomy 21 , but without a disproportionate increase in the asymmetry of the more lateral tooth of each class. This latter observation is in accord with our previous finding that the pattern of tooth size reduction in trisomy $G$ does not resemble that in simple hypodontia.

TABLE

INCREASED BILATERAL ASYMMETRY IN TRISOMY G

\begin{tabular}{|c|c|c|c|c|}
\hline \multirow[b]{2}{*}{ Tooth } & \multicolumn{2}{|c|}{19 Males } & \multicolumn{2}{|c|}{28 Females } \\
\hline & Mongoloid & Normal* & Mongoloid & Normal* \\
\hline $\mathrm{I}^{1}$ & 0.440 & 0.275 & 0.310 & 0.191 \\
\hline $\mathrm{I}^{2}$ & 0.664 & 0.268 & 0.871 & 0.276 \\
\hline $\mathrm{C}$ & 0.308 & 0.240 & 0.250 & 0.190 \\
\hline $\mathbf{P}^{1}$ & 0.426 & 0.190 & 0.480 & 0.178 \\
\hline $\mathbf{p}^{2}$ & 0.394 & 0.218 & 0.376 & 0.210 \\
\hline $\mathbf{M}^{1}$ & 0.447 & 0.260 & 0.673 & 0.261 \\
\hline $\mathbf{M}^{2}$ & 0.621 & 0.309 & 0.549 & 0.415 \\
\hline$I_{1}$ & 0.271 & 0.147 & 0.577 & 0.159 \\
\hline$I_{2}$ & 0.303 & 0.151 & 0.225 & 0.152 \\
\hline $\mathrm{C}$ & 0.251 & 0.174 & 0.233 & 0.195 \\
\hline$P_{1}$ & 0.346 & 0.180 & 0.240 & 0.168 \\
\hline$P_{2}$ & 0.562 & 0.200 & 0.456 & 0.190 \\
\hline $\mathrm{M}_{1}$ & 0.410 & 0.236 & 0.461 & 0.307 \\
\hline $\mathrm{M}_{2}^{1}$ & 0.966 & 0.340 & 0.731 & 0.352 \\
\hline
\end{tabular}

* From Garn, Lewis, and Kerewsky 1966. All values refer to RMS (root mean square) asymmetry in $\mathrm{mm}$. 